\title{
The effect of interstimulus interval on GSR adaptation'
}

Ronald E. Sehaub

DALHOUSIE UNIVERSITY

\section{Abstraet}

The effect of interstimulus interval (ISI) on GSR adaptation was studied in two experiments. In Experiment I three fixed ISIs of 30,60 , and $180 \mathrm{sec}$. were used. Adaptation occurred with the two shorter intervals, but the response first increased and then showed a slight decrement in the $180 \mathrm{sec}$. group. In Experiment II a variable ISI was employed. The results showed that the magnitude of the GSR was a function of the preceding interval. A temporal sensitization factor was proposed to account for these results.

\section{Problem}

One of the difficulties in demonstrating classical conditioning of the GSR is that the response tends to decrease on repeated presentations of either the CS or the US. While this adaptation phenomenon is well known, few systematic studies have appeared on the course of adaptation to a single stimulus within a session. Kimmel (1964) has recently reported a study in which Ss were presented with $207.5 \mathrm{sec}$. visual stimuli at intervals varying from 20 to $40 \mathrm{sec}$. The mean GSR decreased gradually and reached an asymptote somewhere near 18-20 trials. However, Kimmel noted that even within the 20 trials, $24 \%$ of his Ss failed to "adapt-out." Previous studies (e.g., Schaub \& McNulty, 1965) have indicated that the ISI is an important determinant of the adaptation function. The present two experiments were designed to examine two aspects of the ISI: duration and variability.

\section{Method}

Twenty-seven male undergraduates from the Dalhousie University introductory psychology class served as Ss for Experiments I and II. Ss were comfortably seated in the experimental room and told that $\mathrm{E}$ was interested in obtaining some measures in response to certain stimuli, that none of the stimuli were harmful, and that the procedure may be a little boring. Ss were than connected to a Sanborn polygraph equipped to give a continuous skin resistance measure. The GSR was recorded from the index and ring fingers of S's right hand using finger-tip electrodes.

The stimulus, a white noise at $64 \mathrm{db}\left(\right.$ re .0002 dynes $\left./ \mathrm{cm}^{2}\right)$, was delivered to a 3 in speaker about $4 \mathrm{ft}$ above S's head. The white noise source was a Grason-Stadler white noise generator. The stimulus duration of $8 \mathrm{sec}$. was controlled by a Hunter timer. ISIs were timed manually with a stopwatch.

\section{Experiment 1}

Ss were randomly assigned to three groups $(N=5)$ corresponding to three ISIs: 30,60 , and $180 \mathrm{sec}$. Trial 1 began approximately $2 \mathrm{~min}$. after $\mathrm{E}$ left the experimental area. Each group received 20 trials.

\section{Results}

The GSR in conductance change was calculated for each $S$ on each trial. The change measure was based on the resistance level immediately preceding noise onset and the maximum deflection occurring during the noise presentation. Figure 1 shows the mean GSR for blocks of two trials for the different ISI groups. Only the 30 and $60 \mathrm{sec}$. groups showed any evidence of adaptation. Contrary to expectation, the $180 \mathrm{sec}$. group showed an increasing GSR over Trials 1-10, after which a slight decrease occurred. Inspection of the baseline conductance indicated that there were no systemic variations which could account for these GSR changes. An analysis of variance was performed on the "blocked" data and both the effects of ISI $(F=4.22 ; 2,12 \mathrm{df}$; $\mathrm{p}<.05)$ and the ISI $\mathrm{x}$ Trials interaction $(\mathrm{F}=\mathbf{2 . 1 2}$; 18, 108 df; $p<.05)$ were significant. These differences were even more marked when the failures to respond were analyzed. (Failure to respond was arbitrarily defined as a resistance change of less than 500 ohms.) Over the 20 trials, the 30 sec.group showed $49 \%$ failures to respond, the $60 \mathrm{sec}$. group showed $22 \%$, and the 180 sec. group only $3 \%$.

Thus, it appears that the ISI was a powerful factor in determining the magnitude and rate of adaptation of the GSR. One uncontrolled variable in this study was the total time in the experimental situation. For this reason, a second experiment was designed to show the within-subject effect of the ISI.

\section{Experiment 2}

Ss were assigned to an Experimental Group $(\mathrm{N}=6)$ and a Control Group $(\mathrm{N}=6)$. The preliminary procedure was identical to Experiment I except that the first trial began $8 \mathrm{~min}$. after $\mathrm{E}$ left the experimental area. Following Trial 1, the Experimental Group was presented with 18 trials with a variable ISI arranged in the

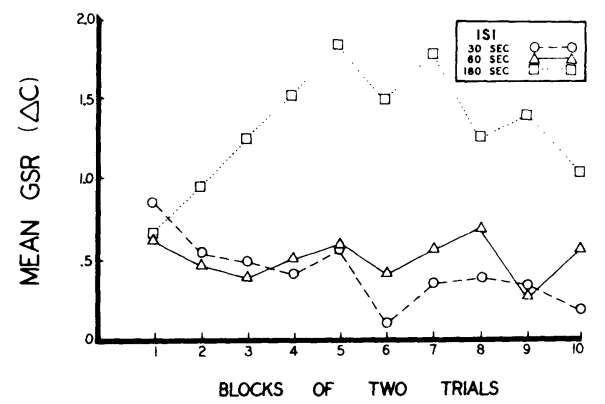

Fig. 1. Mean GSR in blocks of two trials as a function of the interstimulus interval. 
following order: Each consecutive block of three trials contained ISIs of 30,60 , and $120 \mathrm{sec}$. The six possible combinations of these three intervals were presented to each $\mathrm{S}$ with the provision that no two successive stimuli were preceded by the same interval. Finally, the order of the six combinations was varied from $S$ to $S$ so that within each block of three trials each combination was represented equally, and within each trial each interval was represented equally. Thus, the average ISI for the Experimental Group was 70 sec. The Control Group received the same number of trials at a fixed ISI of $70 \mathrm{sec}$.

\section{Results}

The GSR was calculated as in Experiment I. Figure 2 shows the mean GSR for the two groups in blocks of three trials following Trial 1. Superimposed over these data is the mean GSR following e a $\mathrm{ch}$ of the three ISIs in each block for the Experimental Group. The Experimental and Control Groups were compared by performing an analysis of variance on the data. Significance was achieved only for the effect of Blocks of Trials $(F=2.63 ; 5,50 \mathrm{df} ; \mathrm{p}<.05)$. The tendency for the Control Group to show greater adaptation did not approach significance, which possibly resulted from high between-subject variability. Within the Experimental Group a trend is seen for greater GSRs to stimuli preceded by the $120 \mathrm{sec}$. ISI than to those preceded by the other two intervals. This trend was tested by taking the mean response following each interval for each $S$ and submitting these means to a treatments $x$ Ss analysis. The differences were significant beyond the .005 level $(F=12.35 ; 2,10 \mathrm{df})$. Clearly, the differential adaptation rates seen in Experiment I were not merely an effect of total time in the situation since a similar effect is seen in the within-subject design.

\section{Diseussion}

It appears that, under the conditions of the present experiments, the magnitude of the GSR to mild auditory

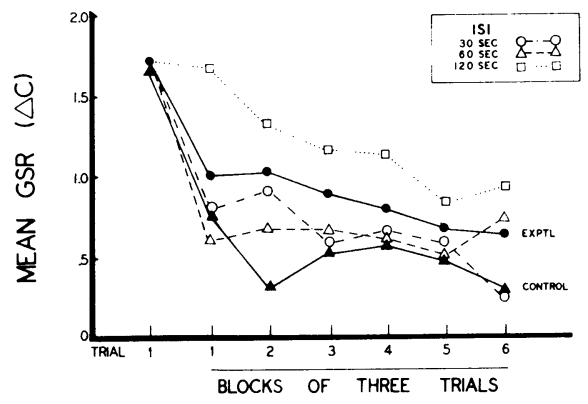

Fig. 2. Mean GSR in blocks of three trials following Trial 1 for Experimental and Control Groups. Dotted functions represent mean response following each ISI within a block for the Experimental Group. adaptation stimuli is a direct function of the ISI. If the interval is sufficiently long ( 3 min.) it appears that little adaptation occurs over the 20 trials. Experiment II demonstrated that the interval effect holds for a variable interval presentation rate, thus questioning the possible hypothesis that Ss in Experiment I developed a temporal "expectancy" which became less accurate for longer intervals.

It is difficult to interpret these findings in terms of any existing model without proposing a new variable. The fact that a long ISI may exist during which no adaptation occurs could be predicted either by Grings' (1960) perceptual disparity concept or by Sokolov's (1963) neuronal model. In either case a flat adaptation function could result from (1) failure of the stimulus trace to persist from one stimulus presentation to the next, thus providing no inhibition on the presentation of subsequent stimuli, or, (2) random noise in the experimental environment causing disinhibition to occur between stimulus presentations. However, neither explanation can account for the in c rea s e in the GSR over Trials 1-10 observed in the $180 \mathrm{sec}$. group. The only apparent solution is to propose a temporal sensitization factor which results in greater GSR activity due merely to the passage of time.

The temporal sensitization factor is further supported by a comparison of the Trial 1 data in the two present experiments. The only difference here is the duration of the "warm-up" period. In Experiment I Ss were left for $2 \mathrm{~min}$. before the presentation of Trial 1 ; in Experiment II this time was $8 \mathrm{~min}$. The mean Trial 1 GSR was twice as great in Experiment II $(t=1.945$; 25 df; $\mathrm{P}<.05$, one tailed).

Finally, the practical significance of these findings should be noted. Frequently, classical conditioning studies of the GSR employ a procedure which involves the introduction of nonreinforced test trials. If a variable presentation rate is used, it is important that the interval preceding test trials be controlled as a possible source of bias.

\section{References}

GRINGS, W. W. Preparatory set variables related to classical conditioning of autonomic responses. Psychol. Rev., 1960, 67, 243-252.

KIMMEL, H. D. Adaptation of the GSR under repeated applications of a visual stimulus. J. exp. Psychol., 1964, 68, 421-422.

SCHAUB, R. E., \& MCNULTY, J. A. Incubation of the galvanic skin response as a function of design and delay characteristics. Psychon. Sci., 1965, 2, 359-360.

SOKOLOV, YE. N. Perception and the conditioned reflex. Oxford: Pergamon Press, 1963.

Note

1. The research reported here was supported in part by Grant No. 9401-22 from the Defence Research Board of Canada to P.H.R. James. 